\title{
Decomposing the Age Effect on Risk Tolerance
}

\section{Postprint.}

For published article see:

Yao, R., Sharpe, D. L., \& Wang, F. (2011). Decomposing the age effect on risk tolerance. Journal of Socio-Economics, 40(6), 879-887.

\begin{abstract}
The importance of investment portfolio allocation has become more apparent since the onset of the late 2000s Great Recession. Individual willingness to take financial risks affects portfolio decisions and investment returns among other factors. Previous research found that people of different ages have dissimilar levels of risk tolerance but the effects of generation, period, and aging were confounded. Using the 1998 to 2007 Survey of Consumer Finances crosssectional datasets, this study uses an analytical method to separate such effects on financial risk tolerance. Aging and period effects on financial risk tolerance were statistically significant. Implications for researchers and financial planning practitioners and educators are provided.
\end{abstract}

\section{JEL Classification}

D12, D14, G11

\section{Keywords}

Attitudes, Generation, Period effect, Risk tolerance, Survey of Consumer Finances 


\section{Introduction}

Several researchers have concluded that Americans are not saving enough to fund their retirement (Warshawsky \& Ameriks, 2000), especially members of the baby boomer generation (VanDerhei \& Copeland, 2011). Although it is without argument that investments have an important place in retirement planning, selection of appropriate investments and investment strategies can be challenging for consumers.

The emergent sub-prime mortgage crisis in the 2000s and the consequent rapid decline in equity value made many investors painfully aware of the importance of having a realistic understanding of financial risks and their own investment risk tolerance. Even seasoned investors saw substantial decreases in their portfolio value. Some decided to take the loss and move to cash. Others, fearing further decline in equity prices as well as weakening currency values moved to gold as a safe haven (Frangos, 2011), driving up the price of gold almost $475 \%$ between 2001 and 2010 (Gold Trades, 2011). Whether moves such as these are prudent resolutions depends on individual situations. It is clear, however, that the deep and prolonged recession that has occurred in the wake of the financial crisis has decreased job security and increased the potential for job loss or salary cutbacks, further increasing financial vulnerability (Bricker, et al., 2011; Keen, 2009).

Retirement safety nets exist in the United States. Nine out of ten retired individuals receive Social Security. For over half of those individuals, Social Security provides $50 \%$ or more of their retirement income (Social Security Administration, 2010). Many retirees also receive monthly payments from a defined benefit plan. These retirement safety nets are shrinking, however. By year 2036, the combined assets of the Social Security Trust Funds will be exhausted (Social Security Board of Trustees, 2011), which implies that future retirees may 
receive less benefit from Social Security. Defined benefit plans are becoming less common today since many employers are switching to defined contribution plans. Consequently, wealth accumulation via market investment has become an essential source of retirement income and retirement planning has become more important than ever.

Research has identified several key factors that can affect wealth accumulation. These factors are broad in scope, ranging from the effect of economic cycles to societal trends, social policies, and individual characteristics. For example, economic conditions change over time, moving from expansion to recession and back again. A tightened credit market can force consumers to save to achieve important financial goals (Bunting, 2009). On an individual level, behavioral economists have identified a number of heuristics and cognitive biases that can adversely influence investment choice and behavior (Tversky \& Kahneman, 1974; Pompian, 2006). Desire to spend on conspicuous consumption can slow wealth accumulation (Yamada, 2008).

Generational effects also exist. Each generation experiences a unique demographic, political, and socioeconomic environment during their formative years. Differing experiences shared by a generation may contribute to dissimilar attitudes towards financial risks between those in different generations. For instance, many of those who experienced the Great Depression tended to remain risk averse for the remainder of their lives (Malmendier \& Nagel, 2009). In contrast, due to sustained government intervention in U.S. financial markets, many members of Generation X had never experienced a down market until the recent Great Recession (Keen, 2009).

Variations in risk preferences may also lead to differences in portfolio allocations that eventually result in wealth inequality. Accurate assessment of risk tolerance is another important 
element in helping to prevent over participation in the market that may result in unnecessary losses, or inadequate market participation that may lead to high opportunity costs, or other financial mistakes such as cashing out when market returns decline and investing when market returns are high.

According to the theory of reasoned action (Fishbein \& Ajzen, 1975), attitudes affect behavior. Investment returns are directly influenced by an individual's portfolio allocation (behavior), which, in turn, should be affected by their willingness to take financial risks (attitudes). Therefore, whether investors are willing to take financial risks; who are more likely to take these risks; how much risk are they willing to take; and what factors affect individuals' willingness to take financial risks become important issues for researchers to investigate.

Researchers have long been aware of the differences in financial risk tolerance of individuals of various ages. These differences have typically been labeled as "the age effect". But this "age effect" is really a combination of three effects: aging, generation, and period. The collective analyses of age, cohort/generation, and period have been employed in marketing research (e.g. Chen, Wong \& Lee, 2001; Rentz \& Reynolds, 1991). The studies that focused on financial risk tolerance have failed to separate these effects, however (e.g. Chaulk, Johnson, \& Bulcroft, 2003; Grable, 2000). What was attributed to an "age effect" may be due to: 1) the decrease of investment horizons and depreciation of human capital as people age (the aging effect); 2) socioeconomic environments that influence different generations and do not change with age (the generation effect); or 3) socioeconomic environments that influence individuals of all ages over time (the period effect). The purpose of this study is to examine the true age effect by decomposing it into these three effects. The following is a review of literature on "the age effect" on risk tolerance and a discussion of the limitations of this prior work. 


\section{Literature Review}

\subsection{The Age Effect on Risk Tolerance}

Much has been written about the effect of age on financial risk tolerance. These studies have adopted different measures of financial risk tolerance. Several studies have used objective measures such as the proportion of risky assets to overall wealth (Ameriks \& Zeldes, 2004; Bertaut, 1998; Bertaut \& Starr-McCluer, 2000; Guiso, Jappelli, \& Terlizzese, 1996; Hui \& Hanna, 1997), whereas other studies used subjective or situational measures such as self-reported risk tolerance level (Chaulk, et al., 2003; Grable, 2000; Hallahan, Faff, \& Mckenzie, 2003; Yao, Gutter, \& Hanna, 2005). Despite the vast amount of research on the effect of age on financial risk tolerance, no consensus has emerged regarding the strength or sign of the relationship.

Most prior research shows that risk tolerance decreases with age (Grable \& Lytton 1998; Morin \& Suarez, 1983; Yao, Hanna, \& Lindamood, 2004; Yao et al., 2005). Morin and Suarez (1983) used the 1970 Canadian Survey of Consumer Finances dataset to study household demand for risky assets. Age was included as a categorical variable ( 35 to $44 ; 45$ to $54 ; 55$ to 64 ; and over 65). They concluded that risk tolerance decreased uniformly with age. Yao et al. (2004) combined the 1983-2001 Survey of Consumer Finances (SCF) cross-sectional datasets and investigated changes in self-perceived financial risk tolerance over time. Similar to Morin and Suarez, age was measured as a series of categorical variables and was found to be negatively related to risk tolerance.

Grable and Lytton (1998) used age as continuous variable and found that self-perceived risk tolerance is negatively related to age. Using the 1983-2001 SCF datasets, Yao et al. (2005) also analyzed the effect of race and ethnicity on subjective financial risk tolerance, measuring age as a continuous variable. The authors concluded that, on average, each additional year increase in age decreased the probability of taking some, high, or substantial risk by $2 \%$. 
Conversely, some studies discovered that age was positively related to risk tolerance (Bertaut, 1998; Grable, 2000; Guiso et al., 1996; Hui \& Hanna, 1997; Zhong \& Xiao, 1995). Using the 1989 SCF, Zhong and Xiao (1995) studied factors that were related to household bond and stock holdings. Age was used as a continuous variable in their Tobit regression. They concluded that age had a positive effect on the dollar value of stock holdings. Guiso et al. (1996) used the dataset from the 1989 Bank of Italy Survey of Household Income and Wealth and investigated the proportion of risky assets in total financial wealth. They included age and age-squared as independent variables and found that younger people held smaller proportions of risky assets in their portfolio (i.e. risk tolerance increases with age). Wang and Hanna (1997) used ratio of risky assets to total wealth in the 1983-1989 SCF panel to examine the effect of age on risk tolerance. They found age had a positive effect on risk tolerance. In her 1998 work, Bertaut also used the 1983-1989 SCF panel data to study the probability of holding stocks. Age, measured as a categorical variable, was found to have a positive relationship with risky behavior so defined.

Using discriminant analysis, Grable (2000) examined whether households were willing to accept above average or below average risk. In his work, data came from a random sample of 1,075 faculty and staff working at southeastern university in 1997. A financial risk-tolerance assessment questionnaire was used to determine respondents' risk tolerance. He found that age had a positive influence on household financial risk tolerance.

Still other studies have shown that risk tolerance had a non-linear pattern with a peak in risk tolerance level occurring around 55 years old (Ameriks \& Zeldes, 2004; Bertaut \& StarrMcCluer, 2000; Chambers \& Schlagenhauf, 2002; Riley \& Chow, 1992). Riley and Chow (1992) found that age had a non-linear effect on the ratio of risky assets to total wealth, that is, risk tolerance increased with age until age 65 and then decreased thereafter. Using data from the 
1989-1998 SCF datasets, Bertaut and Starr-McCluer (2000) examined ownership of risky assets and found that the holding of risky assets had a humped shape with a peak occurring in the 45-54 age group using the 1989 and 1992 SCF data and in the 55-64 age group using the 1995 and 1998 SCF data, which suggested a possible cohort effect. Chambers and Schlagenhauf (2002) analyzed various Wealth Supplements of PSID data and discovered a humped pattern in the amount of stock-holding over the life cycle with the peak occurring in mid-fifties. Ameriks and Zeldes (2004) investigated effect of age and cohort on asset allocation and concluded that the pattern of equity holding was humped-shaped with the highest point occurring between 49 to 58 years old. Grable, McGill, and Britt (2009) found that older working adults were more likely to underestimate their risk tolerance than younger working adults.

\subsection{Generation: A Representation of Social Influence and Its Effect on Risk Tolerance}

The characteristics of a generation can be identified by three attributes: perceived membership, common beliefs and behaviors, and common location in history (Howe \& Strauss, 2000). People of a certain generation are likely to share similar attitudes toward savings and preferences for products and services (Meredith \& Schewe, 1994). These individuals with similar experiences are also likely to exhibit similar willingness to take financial risks that is different from individuals of other generations. For example, most members of generation $\mathrm{X}$ were in high school when Black Monday happened in October 1987. Thus, their attitudes toward risk may be different from that of baby boomers that were in their prime savings years when this event occurred. Ameriks and Zeldes (2004) asserted that if knowledge acquired through firsthand experience has a stronger influence on individual decision than knowledge acquired secondhand, then cohort effects would be important in portfolio decision making. Their statement can be 
interpreted as presenting evidence that generation difference plays a role in risk attitude formation.

Very few studies have examined the differences in risk tolerance between generations. Jianakoplos and Bernasek (2006) employed the 1989, 1995, and 2001 SCF data to investigate differences in financial risk-taking by age, generation and birth cohort. They concluded that, as compared with younger generations, older generations held a larger proportion of investment wealth in risky assets and were more willing to take financial risks.

\subsection{Period Effects on Risk Tolerance}

Risk tolerance has been found to change over time in response to environmental factors. Clarke and Statman (1998) found that newsletter writers' risk tolerance fell dramatically after the stock market crash of 1987. Shefrin (2000) concluded that financial advisors' risk-tolerance levels and market return changes were positively related. Kimball, Sahm and Shapiro (2008) treated the differences in risk tolerance responses over time as measurement errors and Yao et al. (2004) related these differences to patterns of stock market returns. Grable, Lytton and O’Neill (2004) and Grable et al. (2006) also suggested that stock market price changes could explain changes in risk tolerance. Malmendier and Nagel (2009) used the 1964-2004 SCF to examine differences in the effect of macro-economic shocks on long-term risk attitudes. They found that those who had experienced a stock market boom throughout their life were more risk tolerant than those who had not. Also, those experiencing a persistent bull market were more likely to hold stocks and held a higher proportion of wealth in the form of stocks.

\subsection{The Limitations of the Previous Studies}

Studies that have used data collected from one survey year to examine the age effect on risk tolerance (e.g. Grable, 2000; Grable \& Lytton, 1998; Morin \& Suarez, 1983) cannot capture 
the period effect on risk tolerance. Studies that use panel data over multiple years have shortcomings, as well. Wang and Hanna (1997) used the 1983-1989 SCF panel data to study the effect of age on risk tolerance. They failed to include survey year as an independent variable, however, which affected the validity of study results. Bertaut (1998) used the same SCF panel data to examine the age effect on the probability of holding stocks. Rather than combine the data to directly examine the period effect, she ran a separate Probit model for each of the two survey years. This method limits direct comparison of year effects, however.

Yao et al. (2004), Yao et al. (2005), and Bertaut and Starr-McCluer (2000) combined data from multiple survey years and included both age and survey year in their multivariate models. This method separated the period effect from the aggregate age effect. However, the generation effect was still entangled with the aging effect. Jianakoplos and Bernasek (2006) used data from three survey years to investigate the effect of age, generation and birth cohort on financial risktaking. The advantage of this method is that the period effects were made orthogonal to a timetrend (chronological time). However, constraining the year effects to sum to zero over a long time span made the year effects difficult to explain in quantitative terms. This study will address these limitations by combining the SCF data from seven survey years and utilizing a method to break the exact linear dependency relationship between aging, generation, and period to disentangle their effect on risk tolerance.

\section{Methodology}

\subsection{Conceptual Framework and the Hypotheses}

This study proposes that the aggregate measure that has commonly been termed the "age effect" in fact consists of three different effects: the aging effect, the generation effect, and the 
period effect. Figure 1 illustrates the conceptual framework of the collective analysis of the three factors.

[Insert Figure 1 about here]

Both aging and period capture the passage of time. Aging, a measure at the individual level, generally leads to a decreased life expectancy and depreciation in human capital, which would be expected to lead to a lower probability to recover from investment losses. Therefore, as individuals age, they should become less willing to tolerate financial risks.

The period effect measures the influence of changing socioeconomic environments that influence everyone over time, regardless of age. During economic expansion or peak years when investment returns are high and stable, substantial risks may not seem so substantial. However, during unstable economic periods or contraction years, substantial financial risks may seem dreadful. Moreover, perception of risk is also affected by the observation of the behavior of others and the observable consequences of their actions (Fenzl \& Brudermann, 2009). Therefore, individuals may be more risk tolerant when investment returns are high and they observe others receive a large return on investment. Conversely, they may be less risk tolerant when investment returns are low and they observe panic selling of stocks. News reports of market upswings or declines may contribute to the timing and intensity of investor reactions.

Other events may affect people's risk tolerance as well. For example, the Persian Gulf War that began in August 1990 and ended in February 1991 may have reduced people's risk tolerance, although for the entire period the market returns ended up being positive after the initial decline. The terrorist attacks in 2001, the subsequent conflicts in the Middle East, and the internet bubble bust between 2000 and 2002 may have reduced people's risk tolerance; whereas the reduction of tax rates in 2003 for qualified dividends and long-term capital gains may have 
increased their risk tolerance. The net effect of changes such as these on risk tolerance is difficult to assess. However, given the significant changes and events in the socioeconomic and political environment over the years, it is likely that risk tolerances have changed.

Generation is defined as "a cohort-group whose length approximates the span of a phase of life", "whose boundaries are fixed by peer personality", and who have common attitudes and behavior (Strauss \& Howe, 1992). Different generations were born in different years, have lived in different socioeconomic environments as they form their attitudes and, therefore, are influenced by different mass media messages, peer group norms, and ideological schooling. All of these items may contribute to differences in attitude towards financial risks. These differences, which are a result of living through different socioeconomic epochs, tend to not change with age.

Some members of the silent generation experienced the stock market crash in 1929 and the Great Depression. Most of them evidenced global unrest such as World War II and the threat of nuclear war. Growing up, this generation also saw the high volatility of market returns (Standard \& Poor 500 index, www.standardandpoors.com) during the 1930s, 1940s, and 1950s. Participation in the stock market was not a widespread activity. They also lived the majority of their life with limited forms of media and financial events were not a central focus of that media. Knowledge of finances, especially those related to risks, may be scarce for this generation.

During the 1980s, the economy began to grow rapidly and market returns were high. However, these high returns were separated by low or even negative returns every three years. During this period, most baby boomers were between 20s and early 40s and had already started accumulating wealth. Moreover, most boomers experienced the Vietnam War in the 1960s and 
1970s and negative market returns in 1973 and 1974 (between -15\% and -26\%) in their adult years. They also evidenced the Black Monday in October 1987 when they were in their 30s. Members of generation $\mathrm{X}$ experienced consistent high economic performance and high market returns in 1990s when most of them were in their 20s and 30s. This generation did not experience a major market decline until 2001. Type and content of media experienced tremendous growth and change. As compared with prior generations, Generation X is very comfortable with using the Internet where financial information is widely available. Also, much media attention is now focused on financial events and trends. Therefore, this generation is likely to have better knowledge of investment returns and financial risks.

Based on the preceding conceptual framework, the following hypotheses are proposed:

H1: Due to the aging effect, age has a negative effect on risk tolerance.

H2: Due to the period effect, it is expected that respondents in different survey years have different risk tolerance preferences.

H3: Due to the generation effect,

i. baby boomers are more risk tolerant than the silent generation; and ii. generation Xers are more risk tolerant than baby boomers

\subsection{Data}

This study combined the 1989 to 2007 SCF datasets to decompose the "age effect" on financial risk tolerance. The SCF is a survey conducted triennially and supported by the Board of Governors of the Federal Reserve System in cooperation with the Statistics of Income Division of the Internal Revenue Service. The survey provides information on households' financial situations such as income, pension, and information from their balance sheet. This survey also includes information about households' demographic characteristics and their perceptions of 
financial situations. Due to the oversampling of high-income households, the recommended weight (X42001) was used in the descriptive analyses to obtain unbiased estimates for the entire sample households. Since 1989, a consistent multiple imputation method was used by the SCF to provide the best possible estimate for each missing value. As a result, five implicates are generated for each dataset and can be combined into one dataset for statistical analysis using the "repeated-imputation inference" (RII) method (Kennickell \& Woodburn, 1999), which was adopted in this study for analyses.

In the SCF datasets, households with a central couple were arranged so that the "head" of the household was designated to be either the male in a mixed-sex couple household or the older individual in a same-sex couple household, regardless of who was the respondent. When the respondent was someone other than the head, all data for those two individuals were swapped. Such attribution means, in the cases where the swap took place, a risk tolerance level identified with someone was actually the response of another individual. The present study addressed this issue by identifying these households and switching the two involved individuals back so that the effects of demographic, employment, and expectation/attitude variables on financial risk tolerance could be more accurately determined.

To test the hypotheses, members of the silent generation, baby boomers, and generation Xers in each of the 1989 to 2007 SCF datasets were identified and included in the study sample. The total sample size of this study was 21,167.

\subsection{Dependent Variables}

The SCF asks a question to evaluate household financial risk tolerance: 
"Which of the statements on this page comes closest to the amount of financial risk that you and your (husband/wife/partner) are willing to take when you save or make investments?

1. Take substantial financial risks expecting to earn substantial returns

2. Take above average financial risks expecting to earn above average returns

3. Take average financial risks expecting to earn average returns

4. Not willing to take any financial risks"

To meet the criteria for ordered logit, three risk tolerance categories (substantial risk, high risk, and some risk) were constructed. Substantial risk was set equal to 1 if respondent was willing to take substantial risk as defined by the SCF risk tolerance question, 0 otherwise. High risk was coded 1 if respondent indicated willingness to accept either substantial risk or above average risk, 0 otherwise. Some risk was set equal to 1 if respondent indicated willingness to accept either high risk or average risk, 0 otherwise. Therefore, the dependent variables used in the three cumulative logistic models were: substantial risk, high risk, and some risk.

\subsection{Independent Variables}

The independent variables used in the multivariate analysis included generation, survey year, age, other demographic and economic characteristics, and perceptions. The silent generation included respondents who were born between 1928 and 1945; baby boomers were identified as those born between 1946 and 1964; and individuals born between 1965 and 1980 were categorized as generation Xers. The birth year range of baby boomers and generation Xers followed the work of Lancaster and Stillman (2002). They did not separate the silent generation 
from older generations, however. So, this study followed Meredith and Schewe (1994) in defining the silent generation.

Demographic variables included: education, race/ethnicity, household type, presence of related children, home ownership, and employment status. Education included less than high school diploma, high school diploma or GED, some college, bachelor's degree, and graduate or professional degree. Respondents were grouped into four racial/ethnic categories: White, Black, Hispanic, and Other. Household type was defined on the basis of the respondent's gender and marital status and consisted of married males, married females, unmarried males, and unmarried females. Presence of related children and home ownership were dichotomous variables, coded 1 for yes and 0 for no. Employment status consisted of salary earners (working for others), selfemployed individuals, those who were retired/disabled/not working and age 65 or older, or not currently in the labor force and under age 65.

Economic variables included emergency fund adequacy (monetary assets exceed three months' income), level of household income, and level of non-financial assets. Income and nonfinancial assets were log-transformed due to their skewed distributions. The lowest value of income was $\$ 0$. In order to perform the $\log$ transformation, $\$ 1$ was added to all values of income. The lowest value of non-financial assets was $-\$ 33,102.70$; therefore, $\$ 33,103.70$ was added to all non-financial assets values. This technique shifts the distributions of income and non-financial assets up but does not change the shape of the distributions. All dollar amounts were adjusted to 2007 dollars.

Perception variables included whether the respondent expected to receive a substantial inheritance or transfer of assets in the future, investment horizon (one year or less, next few 
years, next 5-10 years, and longer than 10 years), and self-perceived health condition (excellent, good, fair, and poor).

\subsection{Method of Analysis}

A cross-tabulation of risk tolerance and generations and survey year was conducted to observe the percent distribution of risk tolerance in each of these categories. Since there were multiple responses to the risk tolerance question, a multinomial logistic model, an ordered logistic model, and a cumulative logistic model could be used for multivariable analyses, as well as ordinary linear regression.

Ordinary linear regression requires the dependent variable to be continuous. A multinomial logistic model ignores the ordered nature of the four responses. An ordered logistic model assumes parallel regression lines (i.e. the same factors should contribute to the likelihood of taking any level of risks versus the other three). A cumulative logistic model is advantageous because: 1) it allows the dependent variable to be non-linear; 2) it retains the ordered nature of the dependent variable by examining differences between substantial risks vs. lower risks, high risks vs. low risks, and some risks vs. no risk; and 3) it releases the assumption of parallel regression lines in that each independent variable is able to contribute differently to the choice of various levels of risk tolerance. Therefore, a cumulative logistic model was employed in this research. The empirical model is presented as follows:

$$
\log \left(\frac{P_{i}}{1-P_{i}}\right)=\beta_{0}+\beta_{i} X_{i}+\varepsilon_{i}
$$

where $P_{i}$ is the probability of being in a certain risk tolerance category; $X_{i}$ is a vector of independent variables; and $\varepsilon_{\mathrm{i}}$ is the random error. The RII technique was employed in the cumulative logistic analysis to obtain the coefficients, standard deviations, $p$-values, and odds ratios. 
When there is an exact linear dependency problems (grouping respondents into time intervals of the same lengths), four techniques can be employed to solve the problem (Yang \& Land, 2006):

1. Use constraint to make two or more of the remaining age, period, or cohort coefficients to be equal;

2. Use a variable to proxy the cohort or period effects;

3. Make the relationship among age, period, or cohort nonlinear by transforming at least one of the three variables;

4. Recognize the multilevel structure of the individual-level responses and employ a mixed (fix and random effects) model.

Jianakoplos and Bernasek (2006) used the third method listed. The advantage of their method is that the period effects were made orthogonal to a time-trend (chronological time). However, constraining the year effects to sum to zero over a long time span made it difficult to interpret the year effects in any meaningful way.

In this study, respondents were classified into time intervals of different lengths, which broke the exact linear dependency (Yang \& Land, 2008). For example, given the knowledge of a survey year and a generation, it is impossible to identify the exact age of the respondent. However, given the age of the respondent and the survey year, his/her generation can be determined. Therefore, multicollinearity could still be an issue. The Variance Inflation Factor (VIF) is commonly used to identify multicollinearity problems. Values of VIF exceeding 10 are often considered as indicating multicollinearity issues (Freund \& Wilson, 1998). In this analysis, 
the VIF of all variables are less than 7, which indicates that there should be no multicollinearity issues. Therefore, this study included age, year and generation in one model.

\section{Results}

Table 1 presents the percent distribution of risk tolerance levels by generation and year. Results from the cumulative logistic analysis of the likelihood of being more risk tolerant are shown in Table 2. In order to test the significance in the differences between each category of the variables of interest, additional logistic regressions were run with different reference groups. The coefficients and odds ratios are pulled from each set of logistic regression results and presented in Table 3.

[Insert Table 1 about here]

[Insert Table 2 about here]

[Insert Table 3 about here]

\subsection{Aging Effect}

Risk tolerance generally decreased as people age. Table 1 shows this inverse relationship in that the highest risk tolerance was associated with the youngest mean and median age (45.6 and 45 , respectively); and the lowest risk tolerance was associated with the highest mean and median age (47.1 and 47, respectively). As hypothesized, the effect of aging on risk tolerance was negative. Each additional year of age decreased the likelihood of reporting any level of risk tolerance by $2 \%$ (Table 2$)$.

\subsection{Generation Effect}

Of the total respondents, only $4.3 \%$ were willing to take substantial risks; $21.1 \%$ would like to take high risks; and $60.6 \%$ chose to take at least some financial risks (Table 1). The percentage reporting a willingness to take any level of risks is the lowest among members of the 
silent generation (Table 1). A higher percentage of generation Xers were found to be willing to take all levels of risks than boomers. The difference between the percentage of boomers and Xers willing to take some risks was very small (63.2\% and 64.7\%, respectively). As shown in Tables 2 and 3, controlling for other factors, results of the generation effect were inconsistent with the hypotheses in that generation did not make a difference in the likelihood to take any level of risks.

\subsection{Period Effect}

Between 1989 and 1992, the percentage being willing to take high risk increased from $15.8 \%$ to $16.9 \%$ (Table 1 ). During the same time, the likelihood to be willing to take high risk increased 25.0\% (Table 3). From 1995 to 1998, willingness to take high risk and some risk both increased. The percentage being willing to take substantial risk decreased from $5.0 \%$ in 2001 to $3.5 \%$ in 2004 (Table 1). The logistic result in Table 3 was consistent in that respondents in 2004 were only $77.9 \%$ as likely to take substantial risk as those in 2001 . Similarly, the percentage and likelihood to take high risk and some risk also decreased between the two years.

\subsection{Other Factors that Influence Financial Risk Tolerance}

Table 2 shows that education had a positive effect on respondents' willingness to take all levels of financial risks, except that the difference between those with a less than high school education and those who had such a diploma was not statistically significant. Logistic results show that compared to their White counterparts, Blacks and Hispanics were less likely to be willing to take some financial risks but more likely to take substantial risks (Table 2). This result is consistent with previous literature (e.g. Yao et al., 2005). Both married and unmarried females were less risk tolerant than married males at all risk levels. Unmarried males were more likely 
than married males to take substantial and high financial risks. Having dependent children decreased the likelihood of being willing to take some risks by $11.6 \%$.

Being a homeowner increased the likelihood of taking high and some risks by over $30 \%$ (Table 2). Self-employed respondents were more risk tolerant than salary earners at all risk levels. Retired respondents were significantly less risk tolerant than salary earners at the high and some risk levels. Having saved an adequate level of emergency fund increased the likelihood of taking high and some financial risks by $11.9 \%$ and $66.8 \%$, respectively. Higher annual household income had a positive effect on willingness to take high and some financial risks and more nonfinancial assets increased the likelihood of taking all levels of financial risks.

Respondents who expected to receive a substantial amount of inheritance in the future were $22.4 \%$ more likely to take high risks and $30.5 \%$ more likely to take some risks than those who did not have such an expectation (Table 2). Longer investment horizons increased risk tolerance except that the difference between the shortest and longest horizons in substantial risks and the difference between within the next year and next few years in high risks were not statistically significant. Respondents with better health were found to be more likely to take high and some financial risks in general (Table 2). The only non-significant difference was between respondents with poor and fair health in the willingness to take high risks.

\section{Discussion and Implications}

\subsection{Discussion and Implications for Future Research}

Results supported the hypothesis that age has a negative effect on the willingness to take financial risks. There may be more than one reason for this result. Risk means exposure to losses. Age has a pragmatic relationship with financial risk. Each additional year of life represents a shortened time horizon for recouping market losses. In addition, individuals 
approaching or in retirement may shift focus from asset accumulation to asset preservation. These individuals may become relatively more concerned about potential loss of assets needed to fund future desired consumption after labor income ceases.

As people age, they are likely to accumulate investment experience, which could positively influence willingness to accept risk. At the same time, however, advanced age may also be linked to decline in cognitive ability (Fair, 1994). Although respondents to the SCF are asked to report self-perceived health, it is not clear that respondents consider their cognitive ability when giving a response. With declining cognitive ability may become increased concern about ability to appropriately evaluate and manage risk, thus contributing to a tendency to draw back from risk exposure. Future research is needed to measure the acquisition and use of financial knowledge across the life span and the effect of change in that knowledge on risk tolerance. It would also be of interest to use longitudinal data rather than cross-sectional data to capture individual level changes in risk tolerance over the lifespan.

Multivariate results partly confirmed the hypothesis that respondents in different survey years have different risk tolerance preferences (socioeconomic environments influence financial risk tolerance). All three levels of risk tolerance decreased between 2001 and 2004. Tax rates for qualified dividends and long-term capital gains were reduced during this time, which should have encouraged movement into financial markets. But effects of other socioeconomic events such as the 2001 terrorist attacks and bursting of the speculative Internet bubble may have discouraged both risk taking and investment. More research needs to be conducted to further investigate reasons for the changes in financial risk tolerance.

Results generated by both the controlled and uncontrolled results were inconsistent with the last two hypotheses regarding the effect of generation on financial risk tolerance. Only 
$64.7 \%$ of Generation Xers reported a willingness to take some risks. The percentage willing to take substantial or high risks were very low ( $5.9 \%$ and $26.4 \%$, respectively). The relatively low number willing to take risk at any level is somewhat concerning. More so than previous generations, Generation Xers will need to rely on successful investment strategies to build wealth to use in retirement. Employer-provided defined benefit pensions have become rare and sustainability of Social Security is in question. Consequently, it may not be advisable for younger generations to be reluctant to take financial risks and give up opportunities to receive high investment gains.

A recent Federal Reserve survey found that, between 2007 and 2009, 63\% of families experienced a loss in value of housing, investments, or business equity. The median percentage decline in wealth was $45 \%$ (Bricker et al., 2011). Recovery from the effects of the Great Recession will take some time. Although Generation X still has some flexibility in labor-leisure decisions and theoretically could compensate for market loss by increasing the flow of labor income, the Great Recession has made sustained employment somewhat tenuous, at least for the foreseeable future. Generation Xers were between 27 and 42 years old in 2007. These are prime years for investing and building a foundation for future wealth and effort should be made to encourage this generation to make effective investment choices to ensure financial adequacy for the future.

Although investment time horizon is controlled in this study, the longest time horizon available for respondents to choose was "longer than 10 years." Younger generations are likely to have a 20 to 30 year investment horizon. The 2010 Ibbotson Associates annual yearbook (Ibbotson Associates, 2010) indicates that the compound annual rate of return of small-cap stocks ranged from $5.74 \%$ to $21.13 \%$ over the 65 overlapping 20 -year holding periods from 1926 
to 2009 and was the highest return among all asset categories 55 times out of the 65 periods. If these stocks are associated with substantial risk, younger generations with a lengthy investment horizon could consider investing in small-cap stocks via a mutual fund. This strategy would help reduce the unsystematic risks that are associated with direct investment in individual companies.

It is not surprising that the risk tolerance level of self-employed respondents was significantly higher than that of salary earners. Self-employment is an inherently riskier venture than working for a wage or salary. It is also reasonable for households with a higher income to pursue risky investments. Higher income reduces the wage replacement rate of Social Security retirement benefits. Consequently, higher income household need to accumulate relatively more financial wealth to be able to maintain a desired lifestyle in retirement.

\subsection{Implications for Financial Planners}

It is the duty of financial planners to recommend appropriate investment portfolios based on client financial risk tolerance. This study indicates that risk tolerance is not only related to age and period, but it is also affected by households' demographic and economics characteristics and their attitudes and perceptions. A good understanding of their clients' attitude toward risk and how and why such attitudes change is critical. Concern exists that the United States will continue to experience a turbulent economy for some time to come (Keen, 2009). Such an environment may make clients realize that the answers they provided on a risk assessment questionnaire given by their financial planner did not capture their true risk tolerance.

Unnecessary losses may occur if an individual's investment portfolio mismatches his or her risk tolerance, leading to inappropriate portfolio allocation decisions. Client education on financial risk is important so that a client can align personal investment goals with ability to 
tolerate market fluctuations. To help clients in this endeavor, understanding the factors that can influence client financial risk tolerance is an essential task for financial planners.

\subsection{Perception of Financial Risks}

Response to taking a certain level of financial risks may be related to many situations. Differences in respondents' perception regarding the meaning of the terms "substantial" and "average" as descriptors of risk may influence their stated willingness to take financial risks. For example, some individuals may consider investing in any stocks as taking substantial financial risk. Others may perceive the risk associated with stock as "above average" and view such things as options, futures, and direct foreign investment as being "substantial risk." It is likely that different generations have different standard for and measures of financial risks. Consequently, different generations may express different levels of enthusiasm regarding financial risk-taking. It is also possible that individuals will over or under estimate their true risk tolerance (Grable et al., 2009). Future research should endeavor to develop a measure of financial risk tolerance that is independent of such differences in perceptions.

Knowledge of and experiences with investments may also influence differences in the perception of financial risks. Knowledge of investments cannot be simply equated with a person's level of education. For example, a bachelor's degree holder in finance that has invested for 20 years should know a lot more about investing than a Ph.D. degree holder in another field who only started investing a few months ago. Those with modest knowledge about and very little experiences with investments may have a very different perception of financial risks as compared with those who are familiar with investing and have been investing for a long time. Individual's recent experience with investing and their recent portfolio returns may also affect their willingness to take substantial financial risks. For example, if an individual recently lost 
money from a transaction, he or she may be reluctant to repeat the experience and view substantial risks as something to avoid. Further research should be conducted to explore the influence of these factors on individuals' willingness to take financial risks. 


\section{References}

Ameriks, J., Zeldes, S. P. 2004, September. How do household portfolio shares vary with age? working paper. New York: Columbia Unversity Business School. Retrieved March 15, 2010 from http://bear.cba.ufl.edu/karceski/fin6930/lecture\%20notes/Ameriks_Zeldes.pdf

Bertaut, C. C. 1998. Stockholding behavior of U.S. households: Evidence from the 1983-1989 Survey of Consumer Finances. Review of Economics and Statistics, 80 (2) , 263-275.

Bertaut, C. C., Starr-McCluer, M. 2000. Household portfolios in the United States. Federal Reserve Board of Governors. Retrieved May 21, 2010 from http://www.federalreserve.gov/pubs/feds/2000/200026/200026pap.pdf

Bricker, J., Bucks, B., Kennickell, A., Mach, T., Moore, K. (2011) Surveying the aftermath of the storm: Changes in family finances from 2007 to 2009. Finance and Economic Discussion Series, Divisions of Research and Statistics and Monetary Affairs. Federal Reserve Board. Washington, DC.

Bunting, D. 2009. The saving decline: Macro-facts, micro-behavior. Journal of Economic Behavior and Organization, 7 (1-2), 282-295.

Chambers, M., Schlagenhauf, D. E. 2002. Household portfolio allocations, life cycle effects and anticipated inflation. Meeting of the Society for Economic Dynamics.

Chaulk, B., Johnson, P. J., Bulcroft, R. 2003. Effects of marriage and children on financial risk tolerance: A synthesis of family development and prospect theory. Journal of Family and Economic Issues, 24 (3), 257-279.

Chen, R., Wong, K. A., Lee, H. C. 2001. Age, period, and cohort effects on life insurance purchases in the U.S.. The Journal of Risk and Insurance, 68 (2), 303-328.

Clarke, R. G., Statman, M. 1998. Bullish or bearish? Financial Analysts Journal, 54, 63-72. 
Fair, R. C. 1994. How fast do old men slow down? The Review of Economics and Statistics 76, $103-118$.

Fenzl, T., Brudermann, T. 2009. Risk behavior in decision-making in a multi-person-setting. The Journal of Socio-Economics, 38, 752-756.

Fishbein, M., Ajzen, I. 1975. Belief, attitude, intention, and behavior: an introduction to theory and research. Reading, MA: Addison-Wesley.

Frangos, A. 2011. Weaker dollar, gold price hits Marvell profit. Wall Street Journal On-Line, Retrieved June 13, 2011 from http://online.wsj.com/article/SB10001424052702303714704576382820524134948.html

Freund, R. J., Wilson, W. J. 1998. Regression analysis. San Diego, CA: Academic Press.

Gold Trades. 2011. 2011 Gold price trend forecast. January 17. Retrieved June 13, 2011 from http://www1.goldtrades.info/index.php/weekly-analysis/gold-price-forecasts

Grable, J. E. 2000. Financial risk tolerance and additional factors that affect risk taking in everyday money matters. Journal of Business and Psychology, 14 (4), 625-630.

Grable, J. E., Lytton, R. H. 1998. Investor risk tolerance: Testing the efficacy of demographics as differentiating and classifying factors. Financial Counseling and Planning, 9, 61-73.

Grable, J. E., Lytton, R. H., O’Neill, B. 2004. Projection bias and financial risk tolerance. The Journal of Behavioral Finance, 5 (3), 142-147.

Grable, J. E., Lytton, R. H., O'Neill, B., Joo, S-H., Klock, D. 2006. Risk tolerance, projection bias, vividness and equity prices. Journal of Investing, 15 (2), 68--74.

Grable, J. E., McGill, S., Britt, S. 2009. Risk tolerance estimation bias: The age effect. Journal of Business and Economics Research, 7 (7), 1-12. 
Guiso, L., Jappelli, T., Terlizzese, D. 1996. Income risk, borrowing constraints, and portfolio choice. American Economic Review, 86 (1), 158-172.

Hallahan, T. A., Faff, R. W., Mckenzie, M. D. 2003. An exploratory investigation of the relation between risk tolerance scores and demogrphic characteristics. Journal of Multinational Financial Management, 13, 483-502.

Howe, N. Strauss, W. 2000. Millennials rising: The next great generation. New York: Vintage Books.

Hui, W., Hanna, S. 1997. Does risk tolerance decrease with age? Financial Counseling and Planning, 8 (2), 27-31.

Ibbotson Associates. 2010. Stocks, bonds, bill, and inflation 2010 yearbook. Chicago: Ibbotson Associates.

Jianakoplos, N. A., Bernasek, A. 2006. Financial risk taking by age and birth cohort. Southern Economic Journal, 72 (4) , 981-1001.

Keen, S. 2009. Bailing out the Titanic with a thimble. Economic Analysis \& Policy, 39 (1), 324.

Kennickell, A. B. Woodburn, L. R. 1999. Consistent weight design for the 1989, 1992, and 1995 SCFs and the distribution of wealth. Review of Income and Wealth, 45 (2), 193-215.

Kimball, M. S., Sahm, C. R., Shapiro, M. D. 2008. Imputing risk tolerance from survey responses. Journal of the American Statistical Association, 103 (483), 1028-1038.

Lancaster, L. C., Stillman, D. 2002. When generations collide. Who they are. Why they clash. How to solve the generational puzzle at work. New York: Collins Business. 
Malmendier U., Nagel S. (2009): Depression babies: Do macroeconomic experiences affect risktaking? NBER working paper 14813. Retrieved June 13, 2011 from http://www.nber.org/papers/w14813

Meredith, G. P., Schewe, C. 1994. The power of cohorts. American Demographics, 16 (12), 2231.

Morin, R. A., Suarez, A. E. 1983. Risk aversion revisited. The Journal of Finance, 38, 12011216.

Pompian, M M 2006 Behavioral finance and wealth management. Hoboken, N. J.: John Wiley and Sons.

Rentz, J. O., Reynolds, F. D. 1991. Forecasting the effects of an aging population on product consumption: An age-period-cohort framework. Journal of Marketing Research, 28 (3), 355360.

Riley, W. B., Chow, K. V. 1992. Asset allocation and individual risk aversion. Financial Analysts Journal, 48, 32-37.

Shefrin, H. 2000. Beyond greed and fear: Understanding behavioral finance and the psychology of investing. Cambridge, MA: Harvard Business School Press, 2000.

Social Security Administration. 2010. Fast facts and figures about Social Security, 2010. SSA Publication No. 13-11785. Office of Retirement and Disability Policy. Office of Research, Evaluation, and Statistics. Washington, DC. Retrieved June 10, 2011 from http://www.ssa.gov/policy/docs/chartbooks/fast_facts/2010/fast_facts10.pdf

Social Security Board of Trustees. 2011. Projected trust fund exhaustion one year sooner. Retrieved June 23, 2011 from http://www.ssa.gov/pressoffice/pr/trustee11-pr.htm 
Strauss, W., Howe, N. 1992. Generations: the history of America's future 1584 to 2069. New York: William Morrow.

Tversky, D., Kahneman, A. 1974. Judgment under uncertainty: Heuristics and biases. Science, 185 (4157), 1124-1131.

VanDerhei, J., Copeland, C. 2011. The impact of deferring retirement age on retirement income adequacy. Employee Benefit Research Institute. Issue Brief No. 358. Retrieved June 7, 2011 from http://www.ebri.org/pdf/briefspdf/EBRI_IB_06-2011_No358_Defr-Ret.pdf

Wang, H., Hanna, S. D. 1997. Does risk tolerance decrease with age? Financial Counseling and Planning, 8 (2), 27-31.

Warshawsky, M. J., Ameriks, J. 2000. How prepared are Americans for retirement? In O. S. Mitchell, P. B. Hammond, and A. M. Rappaport Eds., Forecasting Retirement Needs and Retirement Wealth pp. 33--67. Philadelphia: University of Pennsylvania Press.

Yamada, K. 2008. Macroeconomi implications of conspicuous consumption: A Sombartian dynamic model, 67, 322-337.

Yang, Y., Land, K. C. 2006. A mixed models approach to the age-period-cohort analysis of repeated cross-section surveys: Trends in verbal test scores. Sociological Methodology, 36, 75-97.

Yang, Y., Land, K. C. 2008. Age-period-cohort analysis of repeated cross-section surveys: Fixed or random effects? Sociological Methods and Research, 36 (3), 297-326.

Yao, R., Gutter, M. S., Hanna, S. D. 2005. The financial risk tolerance of Blacks, Hispanics and Whites. Financial Counseling and Planning, 16 (1), 51-62.

Yao, R., Hanna, S. D., Lindamood, S. 2004. Changes in financial risk tolerance, 1983-2001. Financial Services Review, 13 (4), 249-266. 
Zhong, L. X., Xiao, J. J. 1995. Determinants of family bond and stock holdings. Financial Counseling and Planning, 6 , 107-114. 
Table 1

Percent Risk Tolerance Level by Age, Generation and Year

\begin{tabular}{lcccccc}
\hline Parameter & \multicolumn{2}{c}{ Substantial Risk } & \multicolumn{2}{c}{ High Risk } & \multicolumn{2}{c}{ Some Risk } \\
& $\#$ & \% & $\#$ & \% & \# & \% \\
\hline Total & 1,057 & $4.29 \%$ & 5,187 & $21.05 \%$ & 14,923 & $60.55 \%$ \\
Mean Age & 45.6 & & 46.4 & & 47.1 & \\
Median Age & 45.0 & & 47.0 & & 47.0 & \\
Generation & & & & & & \\
$\quad$ Silent & 174 & $2.68 \%$ & 866 & $13.34 \%$ & 3366 & $51.81 \%$ \\
Boomers & 519 & $4.32 \%$ & 2702 & $22.49 \%$ & 7589 & $63.17 \%$ \\
$\quad$ Xers & 364 & $5.93 \%$ & 1619 & $26.38 \%$ & 3968 & $64.66 \%$ \\
Year & & & & & & \\
1989 & 115 & $5.09 \%$ & 356 & $15.75 \%$ & 1286 & $56.84 \%$ \\
1992 & 114 & $3.75 \%$ & 510 & $16.85 \%$ & 1670 & $55.18 \%$ \\
1995 & 139 & $3.89 \%$ & 694 & $19.38 \%$ & 2127 & $59.36 \%$ \\
1998 & 209 & $5.59 \%$ & 958 & $25.59 \%$ & 2457 & $65.60 \%$ \\
2001 & 201 & $5.04 \%$ & 982 & $24.66 \%$ & 2535 & $63.65 \%$ \\
2004 & 142 & $3.46 \%$ & 842 & $20.44 \%$ & 2464 & $59.85 \%$ \\
2007 & 137 & $3.49 \%$ & 845 & $21.50 \%$ & 2384 & $60.68 \%$ \\
\hline
\end{tabular}

Analysis of the 1989 - 2007 Survey of Consumer Finances datasets, weighted results. 
Table 2 Cumulative Logistic Analysis of the Likelihood of being More Risk Tolerant

\begin{tabular}{|c|c|c|c|c|c|c|c|c|c|}
\hline \multirow{3}{*}{$\begin{array}{l}\text { Parameter } \\
\text { Intercept }\end{array}$} & \multicolumn{3}{|c|}{ Substantial Risk } & \multicolumn{3}{|c|}{ High Risk } & \multicolumn{3}{|c|}{ Some Risk } \\
\hline & \multicolumn{2}{|c|}{ Coefficient } & \multirow[t]{2}{*}{$\begin{array}{l}\text { Odds } \\
\text { Ratio } \\
\end{array}$} & \multicolumn{2}{|c|}{ Coefficient } & \multirow[t]{2}{*}{$\begin{array}{l}\text { Odds } \\
\text { Ratio } \\
\end{array}$} & \multicolumn{2}{|c|}{ Coefficient } & \multirow[t]{2}{*}{$\begin{array}{l}\text { Odds } \\
\text { Ratio } \\
\end{array}$} \\
\hline & -13.5203 & $* * *$ & & -9.9824 & $* * *$ & & -10.8700 & $* * *$ & \\
\hline Age & -0.0212 & $* * *$ & 0.979 & -0.0233 & *** & 0.977 & -0.0172 & $* * *$ & 0.983 \\
\hline \multicolumn{10}{|c|}{ Generation $($ reference category $=$ Silent $)$} \\
\hline Boomer & -0.1611 & & 0.851 & 0.0086 & & 1.009 & 0.0539 & & 1.055 \\
\hline GenX & -0.0753 & & 0.927 & 0.0042 & & 1.004 & 0.0728 & & 1.075 \\
\hline \multicolumn{10}{|l|}{ Year } \\
\hline 1992 & -0.1007 & & 0.904 & 0.2229 & $* *$ & 1.250 & -0.0816 & & 0.922 \\
\hline 1995 & -0.1446 & & 0.865 & 0.2570 & & 1.293 & 0.0746 & & 1.077 \\
\hline 1998 & 0.0214 & & 1.022 & 0.5595 & $* * *$ & 1.750 & 0.3012 & $* *$ & 1.352 \\
\hline 2001 & -0.0336 & & 0.967 & 0.4841 & $* * *$ & 1.623 & 0.1976 & & 1.219 \\
\hline 2004 & -0.2833 & & 0.753 & 0.2158 & & 1.241 & 0.0097 & & 1.010 \\
\hline 2007 & -0.2216 & & 0.801 & 0.3204 & $*$ & 1.378 & 0.1242 & & 1.132 \\
\hline \multicolumn{10}{|c|}{ Education (reference category=Less than High School Diploma) } \\
\hline High School Diploma/GED & 0.2668 & & 1.306 & 0.3319 & *** & 1.394 & 0.5931 & $* * *$ & 1.810 \\
\hline Some College & 0.4581 & $* *$ & 1.581 & 0.6971 & $* * *$ & 2.008 & 1.0889 & $* * *$ & 2.971 \\
\hline Bachelor's Degree & 0.5366 & $* * *$ & 1.710 & 1.0487 & $* * *$ & 2.854 & 1.6141 & $* * *$ & 5.023 \\
\hline Graduate/Professional Degree & 0.5498 & $* * *$ & 1.733 & 1.1415 & $* * *$ & 3.131 & 1.7705 & $* * *$ & 5.874 \\
\hline \multicolumn{10}{|l|}{ Race (reference category $=$ White) } \\
\hline Black & 0.2460 & * & 1.279 & -0.0815 & & 0.922 & -0.2526 & $* * *$ & 0.777 \\
\hline Hispanic & 0.3881 & $* *$ & 1.474 & -0.0421 & & 0.959 & -0.5928 & $* * *$ & 0.553 \\
\hline Others & -0.1798 & & 0.835 & -0.2243 & & 0.799 & -0.2069 & * & 0.813 \\
\hline \multicolumn{10}{|c|}{ Household Type (reference category=Married Male) } \\
\hline Married Female & -0.3567 & $* * *$ & 0.700 & -0.4575 & $* * *$ & 0.633 & -0.4391 & $* * *$ & 0.645 \\
\hline Unmarried Male & 0.4021 & $* * *$ & 1.495 & 0.2260 & $* * *$ & 1.254 & 0.0711 & & 1.074 \\
\hline Unmarried Female & -0.2318 & * & 0.793 & -0.4283 & $* * *$ & 0.652 & -0.5476 & $* * *$ & 0.578 \\
\hline Presence of Related Children & 0.0256 & & 1.026 & -0.0431 & & 0.958 & -0.1228 & $* * *$ & 0.884 \\
\hline Homeowners & 0.0395 & & 1.040 & 0.2720 & $* * *$ & 1.313 & 0.3265 & $* * *$ & 1.386 \\
\hline \multicolumn{10}{|c|}{ Employment Status (reference category=Salary Earner) } \\
\hline Self-employed & 0.5220 & $* * *$ & 1.685 & 0.2677 & *** & 1.307 & 0.2999 & $* * *$ & 1.350 \\
\hline Retired & -0.1208 & & 0.886 & -0.1329 & * & 0.876 & -0.2221 & $* * *$ & 0.801 \\
\hline Not Currently Working & -0.0041 & & 0.996 & -0.0163 & & 0.984 & 0.0449 & & 1.046 \\
\hline Adequate Emergency Fund & 0.0866 & & 1.090 & 0.1122 & ** & 1.119 & 0.5116 & $* * *$ & 1.668 \\
\hline Log(annual household income) & 0.0234 & & 1.024 & 0.0980 & $* * *$ & 1.103 & 0.2143 & $* * *$ & 1.239 \\
\hline $\log ($ non-financial assets) & 0.6550 & $* * *$ & 1.925 & 0.4390 & $* * *$ & 1.551 & 0.4893 & $* * *$ & 1.631 \\
\hline Expect to Receive Inheritance & 0.0174 & & 1.018 & 0.2018 & *** & 1.224 & 0.2665 & $* * *$ & 1.305 \\
\hline \multicolumn{10}{|c|}{ Horizon (reference category $=$ Within Next Year) } \\
\hline Next Few Years & -0.1892 & * & 0.828 & 0.0258 & & 1.026 & 0.2421 & $* * *$ & 1.274 \\
\hline 5 to 10 years & -0.1610 & * & 0.851 & 0.1711 & $* * *$ & 1.187 & 0.3899 & $* * *$ & 1.477 \\
\hline
\end{tabular}




\begin{tabular}{lcrrrrrrr} 
Longer than 10 Years & 0.0969 & 1.102 & 0.2392 & $* * *$ & 1.270 & 0.4599 & $* * *$ & 1.584 \\
Self-perceived Health (reference category=Poor) & & & & & & & \\
Excellent & 0.2337 & 1.263 & 0.4354 & $* * *$ & 1.546 & 0.7061 & $* * *$ & 2.026 \\
Good & 0.0689 & 1.071 & 0.2980 & $*$ & 1.347 & 0.6599 & $* * *$ & 1.935 \\
Fair & 0.1631 & 1.177 & 0.1565 & & 1.169 & 0.3438 & $* * *$ & 1.410 \\
Concordance & 68.1 & & 72.7 & & 81.1 & & \\
Chi-sq test of likelihood ratio & 3100.8 & $* * *$ & & 16093.6 & $* * *$ & & 34010.6 & $* * *$ \\
\hline
\end{tabular}
$* \frac{0}{p<0.05, * * p<0.01, * * *} p<0.001$

Analysis of the 1989 - 2007 Survey of Consumer Finances; Multivariate analyses are unweighted, using RII technique. 
Table 3

Additional Logistic Results with Different Reference Categories

\begin{tabular}{|c|c|c|c|c|c|c|c|c|c|}
\hline \multirow{3}{*}{$\begin{array}{l}\text { Parameter } \\
\text { Age }\end{array}$} & \multicolumn{3}{|c|}{ Substantial Risk } & \multicolumn{3}{|c|}{ High Risk } & \multicolumn{3}{|c|}{ Some Risk } \\
\hline & \multicolumn{2}{|c|}{ Coefficient } & \multirow{2}{*}{$\begin{array}{l}\text { Odds } \\
\text { Ratio }\end{array}$} & \multicolumn{2}{|c|}{ Coefficient } & \multirow{2}{*}{$\begin{array}{l}\begin{array}{l}\text { Odds } \\
\text { Ratio }\end{array} \\
0.977\end{array}$} & \multicolumn{2}{|c|}{ Coefficient } & \multirow{2}{*}{$\begin{array}{l}\text { Odds } \\
\text { Ratio }\end{array}$} \\
\hline & -0.0212 & $* * *$ & & -0.0233 & $* * *$ & & -0.0172 & $* * *$ & \\
\hline \multicolumn{10}{|l|}{ Generation } \\
\hline Silent - Boomer & -0.1611 & & 0.851 & 0.0086 & & 1.009 & 0.0539 & & 1.055 \\
\hline Silent - GenX & -0.0753 & & 0.927 & 0.0042 & & 1.004 & 0.0728 & & 1.075 \\
\hline Boomer - GenX & 0.0858 & & 1.090 & -0.0044 & & 0.996 & 0.0189 & & 1.019 \\
\hline \multicolumn{10}{|l|}{ Year } \\
\hline $1989-1992$ & -0.1007 & & 0.904 & 0.2229 & $* *$ & 1.250 & -0.0816 & & 0.922 \\
\hline $1992-1995$ & -0.0439 & & 0.957 & 0.0341 & & 1.035 & 0.1562 & & 1.169 \\
\hline $1995-1998$ & 0.1660 & & 1.181 & 0.3025 & $* * *$ & 1.353 & 0.2267 & $* * *$ & 1.254 \\
\hline $1998-2001$ & -0.0549 & & 0.947 & -0.0754 & & 0.927 & -0.1036 & & 0.902 \\
\hline $2001-2004$ & -0.2497 & $*$ & 0.779 & -0.2683 & $* * *$ & 0.765 & -0.1879 & $* *$ & 0.829 \\
\hline $2004-2007$ & 0.0617 & & 1.064 & 0.1046 & & 1.110 & 0.1145 & & 1.121 \\
\hline
\end{tabular}




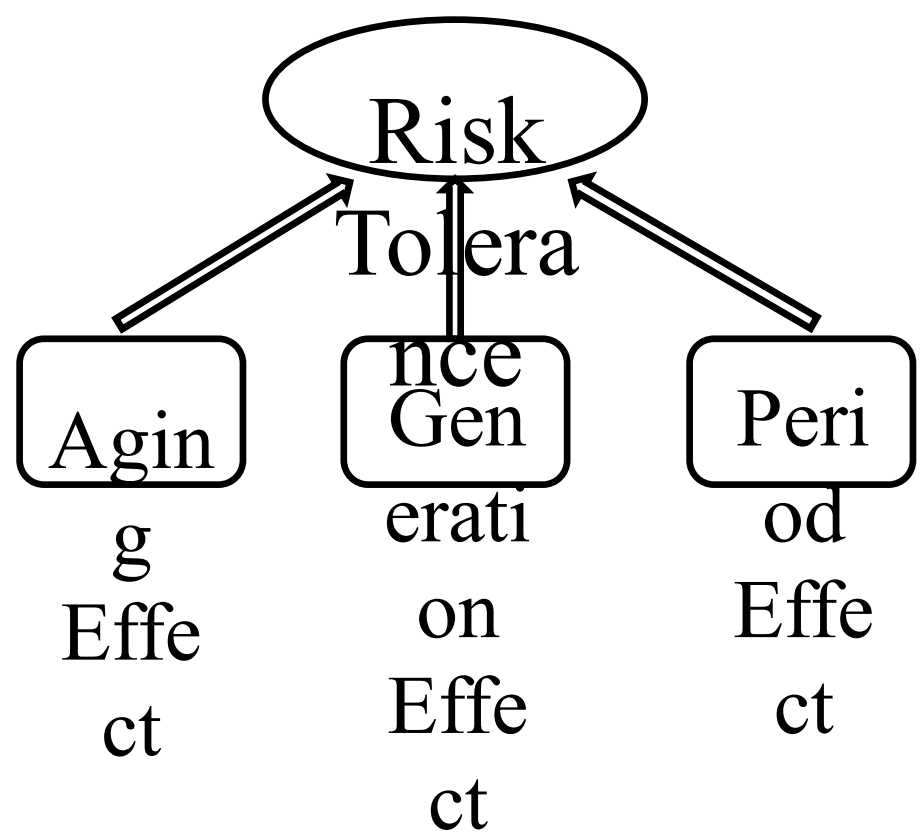

Figure 1. Conceptual Framework

Note: In this study, the three effects are assumed to be independent to focus on the individual influence of each. 